\title{
MANEJo de HeRbicidas Na Cultura da SoJa Roundup Ready ${ }^{\circledR}$
}

\author{
Herbicide Management in Roundup Ready ${ }^{\circledR}$ Soybean Crop
}

\author{
PETTER, F.A. ${ }^{2}$, PROCÓPIO, S.O. ${ }^{3}$, CARGNELUTTI FILHO, A. ${ }^{4}$, BARROSO, A.L.L. ${ }^{5} \mathrm{e}$ \\ PACHECO, L.P. ${ }^{2}$
}

\begin{abstract}
RESUMO - O trabalho objetivou avaliar a eficácia de diferentes sistemas de manejo de herbicidas no controle de plantas daninhas e no desenvolvimento e produtividade de diferentes cultivares de soja Roundup Ready ${ }^{\circledR}$. O delineamento experimental utilizado foi o de blocos ao acaso, com quatro repetições, em esquema fatorial $5 \mathrm{x} 5$, sendo cinco sistemas de aplicação de herbicidas [(1) glyphosate (1.080 $\left.\mathrm{g} \mathrm{ha}^{-1}\right)+2,4-\mathrm{D}\left(241,8 \mathrm{~g} \mathrm{ha}^{-1}\right) 14$ dias antes da semeadura (DAS), paraquat + diuron $\left(400+200 \mathrm{~g} \mathrm{ha}^{-1}\right)$ no dia da semeadura e glyphosate (960 $\left.\mathrm{g} \mathrm{ha}^{-1}\right) 35$ dias após a emergência da cultura (DAE); (2) glyphosate $\left(1.080 \mathrm{~g} \mathrm{ha}^{-1}\right)+2,4-\mathrm{D}$ $\left(241,8 \mathrm{~g} \mathrm{ha}^{-1}\right)$ aos 14 DAS, paraquat + diuron $\left(400+200 \mathrm{~g} \mathrm{ha}^{-1}\right)$ no dia da semeadura e glyphosate (480 $\left.\mathrm{g} \mathrm{ha}^{-1}\right)$ aos $17 \mathrm{DAE}$; (3) glyphosate $\left(1.080 \mathrm{~g} \mathrm{ha}^{-1}\right)+2,4-\mathrm{D}\left(241,8 \mathrm{~g} \mathrm{ha}^{-1}\right)$ aos 14 DAS e glyphosate (960 $\left.\mathrm{g} \mathrm{ha}^{-1}\right)$ aos $35 \mathrm{DAE}$; (4) glyphosate $\left(1.080 \mathrm{~g} \mathrm{ha}^{-1}\right)+2,4-\mathrm{D}\left(241,8 \mathrm{~g} \mathrm{ha}^{-1}\right)$ aos 14 DAS e glyphosate (480 $\left.\mathrm{g} \mathrm{ha}^{-1}\right) 17$ dias após a emergência das plantas; e (5) testemunha glyphosate $\left(1.080 \mathrm{~g} \mathrm{ha}^{-1}\right)+2,4-\mathrm{D}\left(241,8 \mathrm{~g} \mathrm{ha}^{-1}\right)$ aos $14 \mathrm{DAS}$, sem aplicação de herbicidas em pós-emergência] combinados com cinco cultivares de soja RR ${ }^{\circledR}$ (M-SOY 8585, P98R91, Valiosa, CD 219 e TMG 108), formando 25 tratamentos. Todos os sistemas de aplicação de herbicidas apresentaram controle das espécies de plantas daninhas Chamaesyce hirta, Alternanthera tenella, Euphorbia heterophylla, Spermacoce latifolia e Tridax procumbens superior ao da testemunha sem aplicação de herbicidas em pós-emergência, sendo eficientes no controle dessas espécies. No entanto, no "sistema 3" observou-se menor nível de controle das espécies Spermacoce latifolia, Tridax procumbens e Chamaesyce hirta, esta última somente nas parcelas semeadas com o cultivar CD 219. Os sistemas de manejo de herbicidas influenciaram a altura das plantas de soja, sendo os menores valores verificados no cultivar TMG 108 com a aplicação do "sistema 3". A produtividade de grãos dos cultivares de soja não diferiu entre os sistemas de aplicação de herbicidas, porém todos resultaram em produtividade superior ao da testemunha. O cultivar TMG 108 apresentou maior produtividade de grãos em todos os sistemas de aplicação de herbicidas, inclusive nas parcelas da testemunha, mas não diferindo do cultivar P98R91, nos "sistemas 1, 3 e 4" de aplicação de herbicidas e na testemunha, e do cultivar M-SOY 8585, no "sistema 3".
\end{abstract}

Palavras-chave: glyphosate, Glycine max, plantas daninhas.

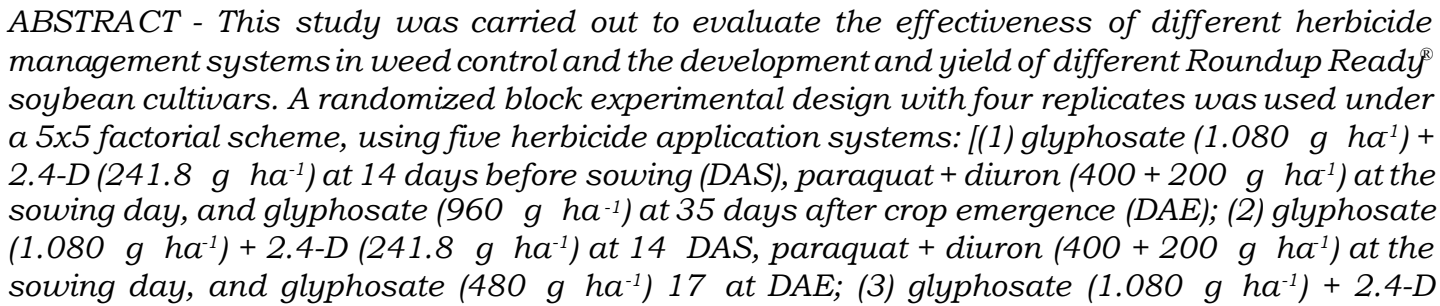

Recebido para publicação em 7.2.2007 e na forma revisada em 31.8.2007.

2 Mestrando do curso de Pós-Graduação em Produção Vegetal da Fesurv - Universidade de Rio Verde, Caixa Postal: 104, 75.901970, Rio Verde-GO; ${ }^{3}$ Pesquisador, Embrapa Tabuleiros Costeiros, Aracaju-SE, 49.025-040, <procopio@cpatc.embrapa.br>; ${ }^{4}$ Professor do Dep. de Estatística da UFRGS, 90.040-060, Porto Alegre-RS; ${ }^{5}$ Professor da Faculdade de Agronomia da Fesurv Universidade de Rio Verde.

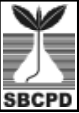

Planta Daninha, Viçosa-MG v. 25, n. 3, p. 557-566, 2007 


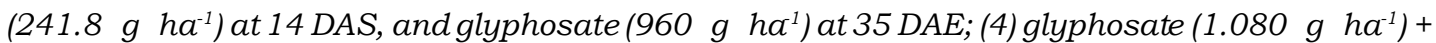
2.4-D (241.8 $\left.\mathrm{g} \mathrm{ha}^{-1}\right)$ at $14 \mathrm{DAS}$ and glyphosate $\left(480 \mathrm{~g} \mathrm{ha}^{-1}\right)$ at 17 days after plantemergence; and (5) control-glyphosate (1.080 $\left.\mathrm{g} \mathrm{ha}^{-1}\right)+2.4-\mathrm{D}\left(241.8 \mathrm{~g} \mathrm{ha}^{-1}\right)$ at $14 \mathrm{DAS}$, withoutherbicide application at post-emergence) combined with five $R R^{\circledR}$ soybean varieties (M-SOY 8585, P98R91, Valiosa, CD 219 and TMG 108),comprising 25 treatments. All herbicide application systems controlled the weed species Chamaesyce hirta, Alternanthera tenella, Euphorbia heterophylla, Spermacoce latifolia and Tridax procumbens. This control was superior to that without herbicide application at post-emergence, being thus efficient in controlling those species. "System 3" showed a lower control level of the species Spermacoce latifolia, Tridax procumbens and Chamaesyce hirta, the last one only in the plots sowed with the cultivar CD 219. Herbicide management systems affected the height of the soybean plants, with the lowest values being found for TMG108 cv. under "system 3" application. Although soybean grain yield did not differ among the herbicide application systems, all were superior to that of the control. TMG $108 \mathrm{cv}$. showed the highest grain yield in all the herbicide application systems even in the control plots; however, it did not differ from P98R91 cv. under the herbicide application "systems 1, 3 and 4 " and in the control, neither from M-SOY $8585 \mathrm{cv}$. under "system 3."

Keywords: glyphosate, Glycine max, weeds.

\section{INTRODUÇÃO}

O controle químico das plantas daninhas é o principal método utilizado nas lavouras de soja do Brasil, principalmente em extensas áreas de produção, as quais são predominantes no cerrado brasileiro. Grande parte das lavouras de soja dessa região é cultivada sob o sistema de plantio direto, sendo o manejo da vegetação presente na área antes da semeadura da cultura realizado com a aplicação de herbicidas, operação designada de "dessecação de manejo”. De acordo com Procópio et al. (2006), a aplicação de herbicidas em dessecação de manejo tornou-se prática obrigatória em cultivos realizados no sistema de plantio direto. O principal herbicida utilizado nessa operação é o glyphosate, pertencente ao grupo químico dos derivados da glicina, que age inibindo a enzima 5-enol-piruvil-shiquimato-3-fosfatosintase (EPSPs), atuante na rota de sintese dos aminoácidos aromáticos (Mendelson, 1998). As principais características do glyphosate que determinam sua alta preferência nas aplicações de dessecação de manejo são o controle de diversas espécies comumente invasoras, independentemente do estádio de crescimento; o controle de espécies de propagação vegetativa; e o fato de não deixar resíduos no solo que acarretem problemas ou atraso na semeadura da cultura. Aplicações de glyphosate em dessecação de manejo têm apresentado controle satisfatório de Digitaria sanguinalis, Digitaria horizontalis e Brachiaria decumbens (Barros, 2001; Jakelaitis et al., 2001; Vangessel et al., 2001a; Maciel \& Constantin, 2002).

Além do glyphosate, outros herbicidas, como 2,4-D, chlorimuron-ethyl, imazethapyr, flumioxazin, diclosulan, carfentrazone-ethyl e sulfentrazone, e a mistura pré-formulada de paraquat e diuron são empregados em dessecação de manejo, sejam associados ao glyphosate ou em aplicações seqüenciais, como é o caso do posicionamento da mistura comercial de paraquat e diuron. Procópio et al. (2006) verificaram controle satisfatório e impedimento da rebrota das plantas daninhas Digitaria insularis e Leptochloa filiformisquando o glyphosate foi aplicado cinco dias antes da semeadura da soja ou quando foi realizada aplicação seqüencial de glyphosate e, posteriormente, da mistura pré-formulada de paraquat e diuron.

Com a liberação do plantio de cultivares de soja Roundup Ready ${ }^{\circledR}\left(\mathrm{RR}^{\circledR}\right)$ no Brasil, a intensidade de uso do glyphosate na cultura, que já era grande, devido às aplicações de dessecação de manejo, passou a ser ainda maior, com a possibilidade de realizar aplicações em pósemergência, ou seja, sobre as plantas de soja geneticamente modificadas. Já na segunda safra após a liberação no País, aproximadamente $35 \%$ de toda a soja cultivada na região Centro-Oeste é formada por cultivares $\mathrm{RR}^{\circledR}$ 
(Biotech Brasil, 2007). Foloni et al. (2005) verificaram que a utilização de glyphosate em pósemergência em soja $R^{\circledR}{ }^{\circledR}$, em área de cerrado, visando o controle de Panicum maximum, Desmodium tortuosum, Eleusine indica, Acanthospermum australe, Tridax procumbens, Chamaesyce hirta, Ipomoea grandifolia e Sida rhombifolia, foi altamente eficiente.

A possibilidade do controle das plantas daninhas em estádio mais avançado, com a utilização do glyphosate, gerou um "esquecimento" dos conceitos dos períodos de convivência das plantas daninhas com a cultura da soja. Períodos de convivência iniciais entre as plantas daninhas e as plantas de soja podem acarretar perdas na produtividade, mesmo que as invasoras sejam controladas posteriormente. De acordo com Pitelli (1985), o periodo anterior à interferência (PAI) situa-se entre 20 e 35 dias após a emergência da cultura da soja. Os períodos de interferência podem variar com as características dos cultivares de soja, como velocidade de estabelecimento, fechamento do dossel e exploração do sistema radicular, e também com a estrutura da comunidade infestante (espécies ocorrentes, densidade populacional e distribuição na lavoura) (Carvalho \& Velini, 2001). A semeadura de cultivares menos suscetiveis à interferência das plantas daninhas é uma prática extremamente importante no manejo integrado, sobretudo quando associada a um eficiente sistema de aplicação de herbicidas. Segundo Pires et al. (2005), um fator que pode facilitar ou dificultar a eficiência do controle químico das plantas daninhas em pósemergência é a velocidade de fechamento do dossel da cultura, característica que pode diferir entre os cultivares de soja. Todavia, devido ao pouco tempo de cultivo e de pesquisas, poucas informações sobre a capacidade competitiva dos principais cultivares de soja $R^{\circledR}$, desenvolvidos para o cerrado brasileiro, em relação às plantas daninhas, foram geradas.

O presente trabalho teve por objetivo avaliar a eficácia de diferentes sistemas de manejos de herbicidas no controle de plantas daninhas e no desenvolvimento e produtividade de diferentes cultivares de soja Roundup Ready ${ }^{\circledR}$.

\section{MATERIAL E MÉTODOS}

O experimento foi conduzido a campo, em área sob sistema de plantio direto, localizada no município de Nova Xavantina-MT, com localização geodésica de $14^{\circ} 41^{\prime} 53^{\prime \prime}$ de latitude e $52^{\circ} 20^{-} 59^{\prime \prime}$ de longitude e altitude de $310 \mathrm{~m}$, no periodo de novembro de 2005 a abril de 2006 , em solo classificado como Latossolo Vermelho distrófico - LVd (Embrapa, 1999).

A composição química e física do solo (0$20 \mathrm{~cm}$ ) presente na área experimental é descrita a seguir: $\mathrm{pH}\left(\mathrm{CaCl}_{2}\right)$ : 5,6; $\mathrm{P}: 10,8 \mathrm{mg} \mathrm{dm}^{-3}$ (método de Mehlich); $\mathrm{K}^{+}: 88,0 \mathrm{mg} \mathrm{dm}^{-3} ; \mathrm{Ca}^{+2}$ : $2,6 \mathrm{cmol}_{\mathrm{c}} \mathrm{dm}^{-3} ; \mathrm{Mg}^{+2}: 0,9 \mathrm{cmol}_{\mathrm{c}} \mathrm{dm}^{-3} ; \mathrm{Al}^{+3}$ : $0,0 \mathrm{cmol}_{\mathrm{c}} \mathrm{dm}^{-3} ; \mathrm{V} \%: 47 ;$ CTC: $8,4 \mathrm{cmol}_{\mathrm{c}} \mathrm{dm}^{-3} ; \mathrm{MO}$ : 24,2 $\mathrm{g} \mathrm{dm}^{-3}$; $\mathrm{S}: 8,7 \mathrm{mg} \mathrm{dm}^{-3}$; Fe: $51,0 \mathrm{mg} \mathrm{dm}^{-3}$; B: $0,4 \mathrm{mg} \mathrm{dm}^{-3} ; \mathrm{Mn}: 41 \mathrm{mg} \mathrm{dm}^{-3} ; \mathrm{Zn}: 2,4 \mathrm{mg} \mathrm{dm}^{-3}$; $\mathrm{Cu}: 1,6 \mathrm{mg} \mathrm{dm}^{-3}$; argila: $43 \%$; silte: $75 \%$; e areia: $35 \%$.

O delineamento experimental utilizado foi o de blocos ao acaso, com quatro repetições, em esquema fatorial $5 \times 5$, sendo cinco sistemas de aplicação de herbicidas (Tabela 1) combinados com cinco cultivares de soja $R^{\circledR}(\mathrm{M}$ SOY 8585, P98R91, Valiosa, CD 219 e TMG 108), constituindo 25 tratamentos. As parcelas foram constituídas por nove linhas da cultura, com $4 \mathrm{~m}$ de comprimento e espaçadas de 0,45 $\mathrm{m}$ entre linhas, totalizando $16,20 \mathrm{~m}^{2}$, sendo a área útil para as avaliações de $9,45 \mathrm{~m}^{2}$.

A semeadura dos cultivares de soja $R^{\circledR}$ foi feita no dia 8 de dezembro de 2005, sobre palhada de milheto, sendo distribuídas $13 \mathrm{se}-$ mentes por metro, na profundidade de $2-3 \mathrm{~cm}$, para todos os cultivares. A adubação de base foi constituída da aplicação de $400 \mathrm{~kg} \mathrm{ha}^{-1} \mathrm{da}$ fórmula 02-18-18.

Os tratamentos foram aplicados utilizando-se um pulverizador costal pressurizado com $\mathrm{CO}_{2}$, acoplado a uma barra contendo quatro pontas de pulverização XR 110.015, aplicandose volume de calda equivalente a $125 \mathrm{~L} \mathrm{ha}^{-1}$.

Aos 46 e 53 dias após a emergência das plantas de soja (DAE), foram realizadas avaliações de controle de plantas daninhas, usando escala percentual variando de 0 a $100 \%$, significando ausência de controle e morte de todas as plantas, respectivamente. A altura de plantas de soja foi avaliada aos $58 \mathrm{DAE}$, amostrando-se cinco plantas ao acaso por parcela. Por ocasião da colheita, também se avaliou a produtividade de grãos, com posterior padronização da umidade em 14\%. 
Tabela 1 - Tratamentos herbicidas utilizados no experimento. Nova Xavantina, MT. 2005/2006

\begin{tabular}{|c|c|c|c|c|}
\hline & $\begin{array}{c}14 \text { dias antes da semeadura } \\
\text { das variedades } \\
\text { de soja RR }{ }^{\circledR}\end{array}$ & $\begin{array}{c}\text { No dia da semeadura } \\
\text { das variedades } \\
\text { de soja RR }{ }^{\circledR}\end{array}$ & $\begin{array}{c}17 \text { dias após a } \\
\text { emergência das plantas } \\
\text { de soja } R^{\circledR}\end{array}$ & $\begin{array}{c}35 \text { dias após a } \\
\text { emergência das plantas } \\
\text { de soja } \mathrm{RR}^{\circledR}\end{array}$ \\
\hline Sistema 1 & $\begin{array}{c}\text { glyphosate }\left(1.080 \mathrm{~g} \mathrm{ha}^{-1}\right)+2,4- \\
\mathrm{D}\left(241,8 \mathrm{~g} \mathrm{ha}^{-1}\right)\end{array}$ & $\begin{array}{l}\text { paraquat }+ \text { diuron } \\
\left(400+200 \mathrm{~g} \mathrm{ha}^{-1}\right)\end{array}$ & - & $\begin{array}{l}\text { glyphosate } \\
\left(960 \mathrm{~g} \mathrm{ha}^{-1}\right)\end{array}$ \\
\hline Sistema 2 & $\begin{array}{c}\text { glyphosate }\left(1.080 \mathrm{~g} \mathrm{ha}^{-1}\right)+2,4- \\
\mathrm{D}\left(241,8 \mathrm{~g} \mathrm{ha}^{-1}\right)\end{array}$ & $\begin{array}{l}\text { paraquat }+ \text { diuron } \\
\left(400+200 \mathrm{~g} \mathrm{ha}^{-1}\right)\end{array}$ & $\begin{array}{l}\text { glyphosate } \\
\left(480 \mathrm{~g} \mathrm{ha}^{-1}\right)\end{array}$ & - \\
\hline Sistema 3 & $\begin{array}{c}\text { glyphosate }\left(1.080 \mathrm{~g} \mathrm{ha}^{-1}\right)+2,4- \\
\mathrm{D}\left(241,8 \mathrm{~g} \mathrm{ha}^{-1}\right)\end{array}$ & - & - & $\begin{array}{l}\text { Glyphosate } \\
\left(960 \mathrm{~g} \mathrm{ha}^{-1}\right) \\
\end{array}$ \\
\hline Sistema 4 & $\begin{array}{c}\text { glyphosate }\left(1.080 \mathrm{~g} \mathrm{ha}^{-1}\right)+2,4- \\
\mathrm{D}\left(241,8 \mathrm{~g} \mathrm{ha}^{-1}\right)\end{array}$ & - & $\begin{array}{l}\text { Glyphosate } \\
\left(480 \mathrm{~g} \mathrm{ha}^{-1}\right)\end{array}$ & - \\
\hline Testemunha & $\begin{array}{c}\text { glyphosate }\left(1.080 \mathrm{~g} \mathrm{ha}^{-1}\right)+2,4- \\
\mathrm{D}\left(241,8 \mathrm{~g} \mathrm{ha}^{-1}\right)\end{array}$ & - & - & - \\
\hline
\end{tabular}

Cinco dias após a última avaliação (53 DAE), realizou-se uma aplicação do inseticida methamidophos (420 $\left.\mathrm{g} \mathrm{ha}^{-1}\right)$ em todas as parcelas experimentais, para que os danos causados por pragas não influenciassem os resultados. Ainda no tocante aos tratos fitossanitários, realizaram-se duas aplicações de fungicidas, sendo a primeira aos $68 \mathrm{DAE}$, de trifloxistrobina + ciproconazol $\left(65,63+28 \mathrm{~g} \mathrm{ha}^{-1}\right)$, e a segunda, aos 88 DAE, do fungicida tebuconazole (100 $\mathrm{g} \mathrm{ha}^{-1}$ ).

Após coleta e tabulação dos dados, estes foram submetidos à análise de variância, sendo as médias das variáveis significativas comparadas pelo teste de Tukey a $5 \%$.

\section{RESULTADOS E DISCUSSÃO}

Todos os sistemas de aplicação de herbicidas apresentaram controle das plantas daninhas avaliadas superior ao da testemunha sem aplicação de herbicidas em pós-emergência.

Nas parcelas onde se encontram os cultivares de soja Roundup $\operatorname{Ready}{ }^{\circledR}\left(\mathrm{RR}^{\circledR}\right) \mathrm{M}$ SOY 8585, P98R91, Valiosa e TMG 108 não foram detectadas diferenças entre os sistemas de aplicação de herbicidas no controle de Chamaesyce hirta, em avaliações realizadas aos 46 e 53 dias após a emergência-DAE (Tabela 2). No entanto, nas áreas semeadas com CD 219, o "sistema 3" apresentou controle inferior dessa espécie daninha, todavia não diferindo aos $53 \mathrm{DAE}$ do controle observado no "sistema 1", que tem como diferencial uma aplicação de paraquat mais diuron no dia da semeadura. A época mais tardia da aplicação do herbicida em pós-emergência - o que propiciou uma aplicação quando as plantas daninhas já se encontravam em estádios mais avançados de crescimento - pode ter dificultado a ação do glyphosate. Também, verificouse que no "sistema 3" de aplicação de herbicidas o controle de $C$. hirta foi menos eficiente nas áreas cultivadas com o cultivar CD 219 , em comparação com as demais variedades de soja $\mathrm{RR}^{\circledR}$ avaliadas (Tabela 2). Isso pode ser devido ao maior tempo gasto por esse cultivar no fechamento do seu dossel, favorecendo o desenvolvimento das plantas daninhas pelo menor sombreamento. Deve-se ressaltar que, mesmo com algumas diferenças detectadas estatisticamente, todos os tratamentos, excetuando os relacionados à testemunha, apresentaram controle acima de $97 \%$ na última avaliação. Resultados semelhantes foram obtidos por Foloni et al. (2005), que, estudando diversas doses e épocas de aplicação de glyphosate em soja $\mathrm{RR}^{\circledR}$, obtiveram controle da espécie de planta daninha C. hirta entre 90 e 98\%.

A espécie Alternanthera tenella foi controlada eficientemente em todos os sistemas de aplicação de herbicidas e em todos os cultivares de soja $R^{\circledR}{ }^{\circledR}$; os níveis de controle não diferiram entre esses tratamentos (Tabela 3). $\mathrm{Na}$ avaliação realizada aos $53 \mathrm{DAE}$, o controle observado dessa invasora pelos tratamentos herbicidas foi superior a $98 \%$.

O controle de Euphorbia heterophylla, aos $46 \mathrm{DAE}$, foi mais eficiente quando o "sistema 1" 
Tabela 2 - Controle de erva-de-santa-luzia (Chamaesyce hirta) após aplicação de herbicidas em cinco variedades de soja Roundup Ready $^{\circledR}$. Nova Xavantina, MT. 2005/2006

\begin{tabular}{|c|c|c|c|c|c|c|}
\hline \multirow{3}{*}{$\begin{array}{l}\text { Sistemas de aplicação de } \\
\text { herbicidas }\end{array}$} & \multicolumn{5}{|c|}{ Variedades de soja Roundup Ready ${ }^{\circledR}$} & \multirow[b]{2}{*}{ Média } \\
\hline & M-SOY 8585 & P98R91 & Valiosa & CD 219 & TMG 108 & \\
\hline & \multicolumn{6}{|c|}{ Controle $(\%)$ aos 46 DAE* } \\
\hline Sistema 1 & $97,75 \mathrm{aA}$ & $95,50 \mathrm{aA}$ & $97,00 \mathrm{aA}$ & $96,75 \mathrm{aA}$ & $98,00 \mathrm{aA}$ & 97,00 \\
\hline Sistema 2 & $98,00 \mathrm{aA}$ & $97,75 \mathrm{aA}$ & $97,75 \mathrm{aA}$ & $97,25 \mathrm{aA}$ & $98,25 \mathrm{aA}$ & 97,80 \\
\hline Sistema 3 & $97,00 \mathrm{aA}$ & $95,25 \mathrm{aA}$ & $97,00 \mathrm{aA}$ & $91,00 \mathrm{bB}$ & $96,50 \mathrm{aA}$ & 95,35 \\
\hline Sistema 4 & $97,75 \mathrm{aA}$ & $98,00 \mathrm{aA}$ & $96,25 \mathrm{aA}$ & $97,75 \mathrm{aA}$ & $96,75 \mathrm{aA}$ & 97,30 \\
\hline Testemunha & $0,00 \mathrm{aB}$ & $0,00 \mathrm{aB}$ & $0,00 \mathrm{aB}$ & $0,00 \mathrm{aC}$ & $0,00 \mathrm{aB}$ & 0,00 \\
\hline Média & 78,10 & 77,30 & 77,60 & 76,55 & 77,90 & 77,49 \\
\hline \multirow{3}{*}{$\begin{array}{l}\text { Sistemas de aplicação de } \\
\text { herbicidas }\end{array}$} & \multicolumn{5}{|c|}{ Variedades de soja Roundup Ready ${ }^{\circledR}$} & \\
\hline & M-SOY 8585 & P98R91 & Valiosa & CD 219 & TMG 108 & Média \\
\hline & \multicolumn{6}{|c|}{ Controle $(\%)$ aos $53 \mathrm{DAE}$} \\
\hline Sistema 1 & $100,00 \mathrm{aA}$ & $98,25 \mathrm{aA}$ & $98,75 \mathrm{aA}$ & $98,75 \mathrm{aAB}$ & $100,00 \mathrm{aA}$ & 99,15 \\
\hline Sistema 2 & $100,00 \mathrm{aA}$ & $100,00 \mathrm{aA}$ & $100,00 \mathrm{aA}$ & $100,00 \mathrm{aA}$ & $100,00 \mathrm{aA}$ & 100,00 \\
\hline Sistema 3 & $99,75 \mathrm{aA}$ & 99,75 a $\mathrm{A}$ & $99,50 \mathrm{aA}$ & $97,25 \mathrm{bB}$ & $98,25 \mathrm{aA}$ & 98,90 \\
\hline Sistema 4 & $100,00 \mathrm{aA}$ & $100,00 \mathrm{aA}$ & $99,50 \mathrm{aA}$ & $100,00 \mathrm{aA}$ & $100,00 \mathrm{aA}$ & 99,90 \\
\hline Testemunha & $0,00 \mathrm{aB}$ & $0,00 \mathrm{aB}$ & $0,00 \mathrm{aB}$ & $0,00 \mathrm{aC}$ & $0,00 \mathrm{aB}$ & 0,00 \\
\hline Média & 79,95 & 79,60 & 79,55 & 79,20 & 79,65 & 79,59 \\
\hline
\end{tabular}

Médias seguidas pelas mesmas letras, minúsculas na linha (horizontal) e maiúsculas na coluna (vertical), não diferem estatisticamente entre si pelo teste de Tukey a $5 \%$. DAE = dias após emergência das plantas de soja $R^{\circledR}$.

Tabela 3 - Controle de apaga-fogo (Alternanthera tenella) após aplicação de herbicidas em cinco variedades de soja Roundup Ready ${ }^{\circledR}$. Nova Xavantina, MT. 2005/2006

\begin{tabular}{|c|c|c|c|c|c|c|}
\hline \multirow{3}{*}{$\begin{array}{c}\text { Sistemas de aplicação de } \\
\text { herbicidas }\end{array}$} & \multicolumn{5}{|c|}{ Variedades de soja Roundup Ready ${ }^{\circledR}$} & \multirow[b]{2}{*}{ Média } \\
\hline & M-SOY 8585 & P98R91 & Valiosa & CD 219 & TMG 108 & \\
\hline & \multicolumn{6}{|c|}{ Controle (\%) aos 46 DAE* $^{*}$} \\
\hline Sistema 1 & $98,75 \mathrm{aA}$ & $96,75 \mathrm{aA}$ & $98,00 \mathrm{aA}$ & $97,75 \mathrm{aA}$ & $97,25 \mathrm{aA}$ & 97,70 \\
\hline Sistema 2 & $97,25 \mathrm{aA}$ & $96,50 \mathrm{aA}$ & $97,75 \mathrm{aA}$ & $95,75 \mathrm{aA}$ & $97,25 \mathrm{aA}$ & 96,90 \\
\hline Sistema 3 & $98,00 \mathrm{aA}$ & $97,00 \mathrm{aA}$ & $98,50 \mathrm{aA}$ & $98,00 \mathrm{aA}$ & $98,50 \mathrm{aA}$ & 98,00 \\
\hline Sistema 4 & $98,75 \mathrm{aA}$ & $97,00 \mathrm{aA}$ & $97,25 \mathrm{aA}$ & $97,50 \mathrm{aA}$ & $98,50 \mathrm{aA}$ & 97,80 \\
\hline Testemunha & $0,00 \mathrm{aB}$ & $0,00 \mathrm{aB}$ & $0,00 \mathrm{aB}$ & $0,00 \mathrm{aB}$ & $0,00 \mathrm{aB}$ & 0,00 \\
\hline Média & 78,55 & 77,45 & 78,30 & 77,80 & 78,30 & 78,08 \\
\hline \multirow{3}{*}{$\begin{array}{l}\text { Sistemas de aplicação de } \\
\text { herbicidas }\end{array}$} & \multicolumn{5}{|c|}{ Variedades de soja Roundup Ready ${ }^{\circledR}$} & \\
\hline & M-SOY 8585 & P98R91 & Valiosa & CD 219 & TMG 108 & Média \\
\hline & \multicolumn{6}{|c|}{ Controle (\%) aos 53 DAE } \\
\hline Sistema 1 & $100,00 \mathrm{aA}$ & $100,00 \mathrm{aA}$ & $100,00 \mathrm{aA}$ & $100,00 \mathrm{aA}$ & $100,00 \mathrm{aA}$ & 100,00 \\
\hline Sistema 2 & $99,50 \mathrm{aA}$ & $100,00 \mathrm{aA}$ & $99,50 \mathrm{aA}$ & $98,50 \mathrm{aA}$ & $100,00 \mathrm{aA}$ & 99,50 \\
\hline Sistema 3 & $100,00 \mathrm{aA}$ & $100,00 \mathrm{aA}$ & $100,00 \mathrm{aA}$ & $100,00 \mathrm{aA}$ & $100,00 \mathrm{aA}$ & 100,00 \\
\hline Sistema 4 & $100,00 \mathrm{aA}$ & $100,00 \mathrm{aA}$ & $100,00 \mathrm{aA}$ & $100,00 \mathrm{aA}$ & $100,00 \mathrm{aA}$ & 100,00 \\
\hline Testemunha & $0,00 \mathrm{aB}$ & $0,00 \mathrm{aB}$ & $0,00 \mathrm{aB}$ & $0,00 \mathrm{aB}$ & $0,00 \mathrm{aB}$ & 0,00 \\
\hline Média & 79,90 & 80,00 & 79,90 & 79,70 & 80,00 & 79,90 \\
\hline
\end{tabular}

Médias seguidas pelas mesmas letras, minúsculas na linha (horizontal) e maiúsculas na coluna (vertical), não diferem estatisticamente entre si pelo teste de Tukey a $5 \%$. DAE = dias após emergência das plantas de soja $R^{\circledR}$. 
de aplicação de herbicidas foi associado ao plantio dos cultivares TMG 108 e P98R91, em relação à sua adoção com o cultivar CD 219 , porém não diferindo da associação com os cultivares Valiosa e M-SOY 8585 (Tabela 4). Na avaliação realizada sete dias depois (53 DAE), não mais foram observadas diferenças entre esses tratamentos. Da mesma forma, a aplicação do "sistema 3" foi mais eficiente no controle de $E$. heterophylla nas parcelas cultivadas com o cultivar TMG 108 do que quando associado ao cultivar $\mathrm{CD} 219$, mas não diferindo da combinação desse sistema com a semeadura dos cultivares M-SOY 8585, P98R91 e Valiosa. Essas diferenças também não foram mais observadas na avaliação seguinte (53 DAE) (Tabela 4). A eficiência dos demais sistemas ("2 e 4") foi a mesma, independentemente do cultivar de soja $\mathrm{RR}^{\circledR}$ presente na área. Entre os sistemas de aplicação de herbicidas não se constataram dife renças no controle de $E$. heterophylla, fato que ocorreu em todos os cultivares testados. Todos os sistemas foram superiores à testemunha e se mostraram extremamente eficientes no controle dessa espécie daninha, sendo o menor nível de controle superior a $95 \%$ aos 53 DAE.

O "sistema 1" de aplicação de herbicidas apresentou o melhor controle de Spermacoce latifolia, aos $46 \mathrm{DAE}$, quando implementado nas parcelas que continham o cultivar de soja $R^{\circledR}$ TMG 108, sendo observado controle médio de $89,0 \%$ dessa espécie (Tabela 5). No entanto, na avaliação seguinte (53 DAE), apenas a associação desse sistema com o cultivar CD 219 apresentou eficiência inferior à dos demais cultivares no controle dessa invasora. A eficiência da aplicação do "sistema 3" no controle de $S$. latifolia também variou de acordo com o cultivar de soja presente na área. Aos $46 \mathrm{DAE}$, o menor nivel de controle de $S$. latifolia, utilizando o "sistema 3", foi observado quando este sistema foi associado ao plantio do cultivar CD 219, não diferindo, contudo, da associação com os cultivares P98R91 e Valiosa, na avaliação realizada sete dias após. O comportamento dos "sistemas 2 e 4" de aplicação de herbicidas no controle de $S$. latifolia não foi influenciado pelo cultivar de soja $R^{\circledR}$ (Tabela 5).

No "sistema 3" de aplicação de herbicidas, em que se realizou apenas uma aplicação de dessecação de manejo e uma aplicação em pós-emergência aos $35 \mathrm{DAE}$, observou-se menor eficiência no controle de $S$. latifolia, aos 46 DAE, nas parcelas cultivadas com CD 219 e TMG 108; todavia, nas áreas cultivadas com TMG 108 o controle proporcionado por esse sistema não diferiu daquele dos "sistemas $2 \mathrm{e}$ 4" (Tabela 5). Na avaliação subseqüente (53 DAE), os menores niveis de controle de S. latifolia com o emprego do "sistema 3" se estenderam a todos os cultivares de soja $R^{\circledR}$, apenas não diferindo do "sistema 1" nas áreas cultivadas com o cultivar CD 219. Ressalta-se que, além de se apresentar menos eficiente no controle dessa invasora, o "sistema 3" de aplicação de herbicidas ainda tem como desvantagem a maior dose do herbicida glyphosate na aplicação em pós-emergência (960 g e.a. ha ${ }^{-1}$ ), em relação ao "sistema 4" (480 $\mathrm{g} \mathrm{ha}^{-1}$ de glyphosate), o que eleva os custos de produção e aumenta o aporte desse agroquímico no ambiente. Swanton et al. (2000) obtiveram os melhores resultados no controle de plantas daninhas em soja $R^{\circledR}$ quando se aplicou glyphosate de forma seqüencial, sendo a primeira aplicação em pré-semeadura e a segunda quando a soja estava com um a três trifólios. Novamente, verifica-se que, mesmo havendo diferenças no controle de S. latifolia entre alguns tratamentos, a eficiência demonstrada por todos os sistemas de aplicação de herbicidas nos cultivares de soja $R R^{\circledR}$ foi alta, sendo o menor nível médio de controle superior a $91 \%$.

A combinação dos "sistemas 1,2 e 3" de aplicação de herbicidas com o cultivar de soja $R^{\circledR}{ }^{\circledR} C D 219$ resultou em menor controle da espécie daninha Tridaxprocumbens, aos $46 \mathrm{DAE}$, em relação à associação desses mesmos sistemas com os demais cultivares, apenas não diferindo do "sistema 2", quando este foi empregado nas parcelas com o cultivar P98R91 (Tabela 6). Na avaliação seguinte, observa-se que as associações dos "sistemas 1 e 3 " com o cultivar CD 219 continuaram apresentando menor desempenho no controle de T. procumbens em relação aos outros cultivares. A implementação do "sistema 3" promoveu os menores niveis de controle de T. procumbens nas áreas cultivadas com todos os cultivares de soja $R R^{\circledR}$, nas duas épocas de avaliação (46 e 53 DAE), não diferindo apenas do "sistema 1" nas áreas semeadas com M-SOY 8585 (Tabela 6). Também, observou-se que a 
Tabela 4 - Controle de leiteiro (Euphorbia heterophylla) após aplicação de herbicidas em cinco variedades de soja Roundup Ready $^{\circledR}$. Nova Xavantina, MT. 2005/2006

\begin{tabular}{|c|c|c|c|c|c|c|}
\hline \multirow{3}{*}{$\begin{array}{c}\text { Sistemas de aplicação de } \\
\text { herbicidas }\end{array}$} & \multicolumn{5}{|c|}{ Variedades de soja Roundup Ready ${ }^{\circledR}$} & \multirow[b]{2}{*}{ Média } \\
\hline & M-SOY 8585 & P98R91 & Valiosa & CD 219 & TMG 108 & \\
\hline & \multicolumn{6}{|c|}{ Controle $(\%)$ aos $46 \mathrm{DAE}^{*}$} \\
\hline Sistema 1 & $94,25 \mathrm{abA}$ & $95,75 \mathrm{aA}$ & $95,50 \mathrm{abA}$ & $91,50 \mathrm{bA}$ & $96,25 \mathrm{aA}$ & 94,65 \\
\hline Sistema 2 & $96,50 \mathrm{aA}$ & $96,00 \mathrm{aA}$ & $96,50 \mathrm{aA}$ & $92,75 \mathrm{aA}$ & $95,50 \mathrm{aA}$ & 95,45 \\
\hline Sistema 3 & $94,75 \mathrm{abA}$ & $94,50 \mathrm{abA}$ & $94,25 \mathrm{abA}$ & $92,25 \mathrm{bA}$ & $96,50 \mathrm{aA}$ & 94,45 \\
\hline Sistema 4 & $98,00 \mathrm{aA}$ & $98,00 \mathrm{aA}$ & $98,00 \mathrm{aA}$ & $97,50 \mathrm{aA}$ & $97,50 \mathrm{aA}$ & 97,80 \\
\hline Testemunha & $0,00 \mathrm{aB}$ & $0,00 \mathrm{aB}$ & $0,00 \mathrm{aB}$ & $0,00 \mathrm{aB}$ & $0,00 \mathrm{aB}$ & 0,00 \\
\hline Média & 76,70 & 76,85 & 76,85 & 74,80 & 77,15 & 76,47 \\
\hline \multirow{3}{*}{$\begin{array}{l}\text { Sistemas de aplicação de } \\
\text { herbicidas }\end{array}$} & \multicolumn{5}{|c|}{ Variedades de soja Roundup Ready ${ }^{\circledR}$} & \\
\hline & M-SOY 8585 & P98R91 & Valiosa & CD 219 & TMG 108 & Média \\
\hline & \multicolumn{6}{|c|}{ Controle $(\%)$ aos $53 \mathrm{DAE}$} \\
\hline Sistema 1 & $97,50 \mathrm{aA}$ & $98,25 \mathrm{aA}$ & $98,25 \mathrm{aA}$ & $95,50 \mathrm{aA}$ & $99,00 \mathrm{aA}$ & 97,70 \\
\hline Sistema 2 & $99,75 \mathrm{aA}$ & $100,00 \mathrm{aA}$ & $99,25 \mathrm{aA}$ & $98,50 \mathrm{aA}$ & $99,50 \mathrm{aA}$ & 99,40 \\
\hline Sistema 3 & $98,50 \mathrm{aA}$ & $98,50 \mathrm{aA}$ & $98,50 \mathrm{aA}$ & $98,25 \mathrm{aA}$ & $99,00 \mathrm{aA}$ & 98,55 \\
\hline Sistema 4 & $99,25 \mathrm{aA}$ & $99,50 \mathrm{aA}$ & $100,00 \mathrm{aA}$ & $99,25 \mathrm{aA}$ & $99,75 \mathrm{aA}$ & 99,55 \\
\hline Testemunha & $0,00 \mathrm{aB}$ & $0,00 \mathrm{aB}$ & $0,00 \mathrm{aB}$ & $0,00 \mathrm{aB}$ & $0,00 \mathrm{aB}$ & 0,00 \\
\hline Média & 79,00 & 79,25 & 79,20 & 78,30 & 79,45 & 79,04 \\
\hline
\end{tabular}

Médias seguidas pelas mesmas letras, minúsculas na linha (horizontal) e maiúsculas na coluna (vertical), não diferem estatisticamente entre si pelo teste de Tukey a 5\%. DAE = dias após emergência das plantas de soja $R^{\circledR}$.

Tabela 5 - Controle de erva-quente (Spermacoce latifolia) após aplicação de herbicidas em cinco variedades de soja Roundup Ready $^{\circledR}$. Nova Xavantina, MT. 2005/2006

\begin{tabular}{|c|c|c|c|c|c|c|}
\hline \multirow{3}{*}{$\begin{array}{l}\text { Sistemas de aplicação de } \\
\text { herbicidas }\end{array}$} & \multicolumn{5}{|c|}{ Variedades de soja Roundup Ready ${ }^{\circledR}$} & \multirow[b]{2}{*}{ Média } \\
\hline & M-SOY 8585 & P98R91 & Valiosa & CD 219 & TMG 108 & \\
\hline & \multicolumn{6}{|c|}{ Controle $(\%)$ aos $46 \mathrm{DAE}^{*}$} \\
\hline Sistema 1 & $85,75 \mathrm{bA}$ & $85,00 \mathrm{bA}$ & $85,50 \mathrm{bA}$ & $86,00 \mathrm{bA}$ & $89,00 \mathrm{aA}$ & 86,25 \\
\hline Sistema 2 & $87,50 \mathrm{aA}$ & $86,25 \mathrm{aA}$ & $85,00 \mathrm{aA}$ & $85,25 \mathrm{aA}$ & $87,00 \mathrm{aAB}$ & 86,20 \\
\hline Sistema 3 & 86,75 aA & $87,00 \mathrm{aA}$ & $87,75 \mathrm{aA}$ & $82,25 \mathrm{bB}$ & $85,50 \mathrm{aB}$ & 85,85 \\
\hline Sistema 4 & $88,00 \mathrm{aA}$ & $88,75 \mathrm{aA}$ & $86,50 \mathrm{aA}$ & $86,25 \mathrm{aA}$ & $87,50 \mathrm{aAB}$ & 87,40 \\
\hline Testemunha & $0,00 \mathrm{aB}$ & $0,00 \mathrm{aB}$ & $0,00 \mathrm{aB}$ & $0,00 \mathrm{aC}$ & $0,00 \mathrm{aC}$ & 0,00 \\
\hline Média & 69,60 & 69,40 & 68,95 & 67,95 & 69,80 & 69,14 \\
\hline \multirow{3}{*}{$\begin{array}{l}\text { Sistemas de aplicação de } \\
\text { herbicidas }\end{array}$} & \multicolumn{5}{|c|}{ Variedades de soja Roundup Ready ${ }^{\circledR}$} & \\
\hline & M-SOY 8585 & P98R91 & Valiosa & CD 219 & TMG 108 & Média \\
\hline & \multicolumn{6}{|c|}{ Controle $(\%)$ aos $53 \mathrm{DAE}$} \\
\hline Sistema 1 & $98,75 \mathrm{aA}$ & $98,00 \mathrm{aA}$ & $97,25 \mathrm{aA}$ & $92,75 \mathrm{bB}$ & $99,25 \mathrm{aA}$ & 97,20 \\
\hline Sistema 2 & $100,00 \mathrm{aA}$ & $99,75 \mathrm{aA}$ & $99,75 \mathrm{aA}$ & $97,50 \mathrm{aA}$ & $100,00 \mathrm{aA}$ & 99,40 \\
\hline Sistema 3 & $95,50 \mathrm{aB}$ & $93,25 \mathrm{abB}$ & $94,00 \mathrm{abB}$ & $91,75 \mathrm{bB}$ & $95,75 \mathrm{aB}$ & 94,05 \\
\hline Sistema 4 & $98,50 \mathrm{aA}$ & $98,75 \mathrm{aA}$ & $99,75 \mathrm{aA}$ & $99,00 \mathrm{aA}$ & $100,00 \mathrm{aA}$ & 99,20 \\
\hline Testemunha & $0,00 \mathrm{aC}$ & $0,00 \mathrm{aC}$ & $0,00 \mathrm{aC}$ & $0,00 \mathrm{aC}$ & $0,00 \mathrm{aC}$ & 0,00 \\
\hline Média & 78,55 & 77,95 & 78,15 & 76,20 & 79,00 & 77,97 \\
\hline
\end{tabular}

Médias seguidas pelas mesmas letras, minúsculas na linha (horizontal) e maiúsculas na coluna (vertical), não diferem estatisticamente entre si pelo teste de Tukey a $5 \%$. DAE = dias após emergência das plantas de soja $R^{\circledR}$. 
Tabela 6 - Controle de erva-de-touro (Tridax procumbens) após aplicação de herbicidas em cinco variedades de soja Roundup Ready $^{\circledR}$. Nova Xavantina, MT. 2005/2006

\begin{tabular}{|c|c|c|c|c|c|c|}
\hline \multirow{3}{*}{$\begin{array}{l}\text { Sistemas de aplicação de } \\
\text { herbicidas }\end{array}$} & \multicolumn{5}{|c|}{ Variedades de soja Roundup Ready ${ }^{\circledR}$} & \multirow[b]{2}{*}{ Média } \\
\hline & M-SOY 8585 & P98R91 & Valiosa & CD 219 & TMG 108 & \\
\hline & \multicolumn{6}{|c|}{ Controle $(\%)$ aos 46 DAE$^{*}$} \\
\hline Sistema 1 & $96,75 \mathrm{aAB}$ & $96,25 \mathrm{aA}$ & $96,50 \mathrm{aA}$ & $91,25 \mathrm{bB}$ & $96,25 \mathrm{aA}$ & 95,40 \\
\hline Sistema 2 & $98,25 \mathrm{aA}$ & $96,75 \mathrm{abA}$ & $98,00 \mathrm{aA}$ & $94,50 \mathrm{bA}$ & $98,25 \mathrm{aA}$ & 97,15 \\
\hline Sistema 3 & $93,75 \mathrm{aB}$ & $91,50 \mathrm{aB}$ & $90,75 \mathrm{aB}$ & $85,50 \mathrm{bC}$ & $92,25 \mathrm{aB}$ & 90,75 \\
\hline Sistema 4 & $98,25 \mathrm{aA}$ & $98,25 \mathrm{aA}$ & $98,00 \mathrm{aA}$ & $98,25 \mathrm{aA}$ & $98,25 \mathrm{aA}$ & 98,20 \\
\hline Testemunha & $0,00 \mathrm{aC}$ & $0,00 \mathrm{aC}$ & $0,00 \mathrm{aC}$ & $0,00 \mathrm{aD}$ & $0,00 \mathrm{aC}$ & 0,00 \\
\hline Média & 77,40 & 76,55 & 76,65 & 73,90 & 77,00 & 76,30 \\
\hline \multirow{3}{*}{$\begin{array}{c}\text { Sistemas de aplicação de } \\
\text { herbicidas }\end{array}$} & \multicolumn{5}{|c|}{ Variedades de soja Roundup Ready ${ }^{\circledR}$} & \\
\hline & M-SOY 8585 & P98R91 & Valiosa & CD 219 & TMG 108 & Média \\
\hline & \multicolumn{6}{|c|}{ Controle $(\%)$ aos 53 DAE } \\
\hline Sistema 1 & $99,75 \mathrm{aA}$ & $99,25 \mathrm{aA}$ & $100,00 \mathrm{aA}$ & $95,00 \mathrm{bB}$ & $99,75 \mathrm{aA}$ & 98,75 \\
\hline Sistema 2 & $100,00 \mathrm{aA}$ & $100,00 \mathrm{aA}$ & $100,00 \mathrm{aA}$ & $100,00 \mathrm{aA}$ & $100,00 \mathrm{aA}$ & 100,00 \\
\hline Sistema 3 & $96,50 \mathrm{aB}$ & $94,75 \mathrm{aB}$ & $94,50 \mathrm{aB}$ & $89,50 \mathrm{bC}$ & $96,50 \mathrm{aB}$ & 94,35 \\
\hline Sistema 4 & $99,50 \mathrm{aA}$ & $100,00 \mathrm{aA}$ & $100,00 \mathrm{aA}$ & $100,00 \mathrm{aA}$ & $99,50 \mathrm{aA}$ & 99,80 \\
\hline Testemunha & $0,00 \mathrm{aC}$ & $0,00 \mathrm{aC}$ & $0,00 \mathrm{aC}$ & $0,00 \mathrm{aD}$ & $0,00 \mathrm{aC}$ & 0,00 \\
\hline Média & 79,15 & 78,80 & 78,90 & 76,90 & 79,15 & 78,58 \\
\hline
\end{tabular}

Médias seguidas pelas mesmas letras, minúsculas na linha (horizontal) e maiúsculas na coluna (vertical), não diferem estatisticamente entre si pelo teste de Tukey a 5\%. DAE = dias após emergência das plantas de soja $R^{\circledR}$.

execução do "sistema 1" nas áreas cultivadas com CD 219, apesar de promover melhor controle de T. procumbens em comparação com o "sistema 3", apresentou-se inferior aos resultados proporcionados pelos "sistemas 2 e 4". Como visto no controle das demais espécies de plantas daninhas, o controle de $T$. procumbens demonstrado pela aplicação de todos os sistemas de aplicação de herbicidas, em todas as parcelas cultivadas com os cinco cultivares de soja $R^{\circledR}$, se mostrou eficiente, sendo sempre superior ao da testemunha sem pós-emergência. Apenas no tratamento composto pela associação do "sistema 3" de aplicação de herbicidas com o cultivar CD 219, o controle médio dessa invasora foi levemente inferior a $90 \%$. Esses dados corroboram o controle de T. procumbens verificado por Foloni et al. (2005), em que aplicações de glyphosate em pós-emergência, em lavouras de soja $R^{\circledR}$, proporcionaram controle final entre 90 e 99\%, conforme a dose e a época de aplicação desse herbicida.

O fato de a área experimental ter sido cultivada anteriormente com milheto, exercendo controle cultural das plantas daninhas antes do plantio da soja, aliado a um rápido fechamento do dossel dos cultivares de soja $R^{\circledR}$, pode ter sido determinante na obtenção dos altos niveis de controle das plantas daninhas verificados em todos os sistemas de aplicação dos herbicidas.

A altura das plantas de soja de todos os cultivares avaliados foi influenciada pelos sistemas de aplicação de herbicidas. As plantas do cultivar M-SOY 8585 apresentaram maior altura quando se utilizou o "sistema 1" de aplicação de herbicidas (Tabela 7). Oliveira Júnior et al. (2006) constataram maior altura de plantas de soja, aos 30 dias após semeadura, no sistema de dessecação de manejo denominado "Aplique Plante", em que se realizou a dessecação no mesmo dia do plantio. Para o cultivar P98R91 não foi detectada influência dos tratamentos herbicidas na porte das plantas de soja, não diferindo inclusive das plantas presentes nas parcelas onde não se realizou aplicação de herbicidas em pós-emergência (testemunha). O emprego do "sistema 2", que apresenta duas aplicações de dessecação de manejo e uma aplicação em pós-emergência aos $17 \mathrm{DAE}$, proporcionou plantas mais altas de soja dos cultivares Valiosa e CD 219, mas não diferindo, nesses dois cultivares, dos 
Tabela 7 - Altura de plantas e produtividade de grãos de cinco variedades de soja Roundup Ready ${ }^{\circledR}$, após aplicação de herbicidas . Nova Xavantina, MT. 2005/2006

\begin{tabular}{|c|c|c|c|c|c|c|}
\hline \multirow{3}{*}{$\begin{array}{l}\text { Sistemas de aplicação de } \\
\text { herbicidas }\end{array}$} & \multicolumn{5}{|c|}{ Variedades de soja Roundup Ready ${ }^{\circledR}$} & \multirow[b]{2}{*}{ Média } \\
\hline & M-SOY 8585 & P98R91 & Valiosa & CD 219 & TMG 108 & \\
\hline & \multicolumn{6}{|c|}{ Altura de plantas $(\mathrm{cm})$ aos $54 \mathrm{DAE}^{*}$} \\
\hline Sistema 1 & $69,25 \mathrm{aA}$ & $55,50 \mathrm{bA}$ & $50,50 \mathrm{bAB}$ & $44,25 \mathrm{cABC}$ & $68,50 \mathrm{aA}$ & 57,60 \\
\hline Sistema 2 & $59,00 \mathrm{bB}$ & $58,00 \mathrm{bA}$ & $55,00 \mathrm{bcA}$ & $49,50 \mathrm{cA}$ & $69,25 \mathrm{aA}$ & 58,15 \\
\hline Sistema 3 & $58,75 \mathrm{aB}$ & $55,25 \mathrm{aA}$ & $46,50 \mathrm{bBC}$ & $41,50 \mathrm{bBC}$ & $56,50 \mathrm{aB}$ & 51,70 \\
\hline Sistema 4 & $60,50 \mathrm{aB}$ & $59,25 \mathrm{aA}$ & $50,25 \mathrm{bAB}$ & $45,00 \mathrm{bAB}$ & $64,50 \mathrm{aA}$ & 55,90 \\
\hline Testemunha & $57,00 \mathrm{aB}$ & $54,75 \mathrm{aA}$ & $42,00 \mathrm{bC}$ & $38,50 \mathrm{bC}$ & $58,25 \mathrm{aB}$ & 50,10 \\
\hline Média & 60,90 & 56,55 & 48,85 & 43,75 & 63,40 & 54,69 \\
\hline \multirow{3}{*}{$\begin{array}{l}\text { Sistemas de aplicação de } \\
\text { herbicidas }\end{array}$} & \multicolumn{5}{|c|}{ Variedades de soja Roundup Ready ${ }^{\circledR}$} & \\
\hline & M-SOY 8585 & P98R91 & Valiosa & CD 219 & TMG 108 & Média \\
\hline & \multicolumn{6}{|c|}{ Produtividade de grãos $\left(\mathrm{kg} \mathrm{ha}^{-1}\right)$} \\
\hline Sistema 1 & $2.450 \mathrm{cA}$ & $2.871 \mathrm{abA}$ & $2.650 \mathrm{bcA}$ & $2.075 \mathrm{dA}$ & $3.004 \mathrm{aA}$ & 2.610 \\
\hline Sistema 2 & $2.588 \mathrm{bA}$ & $2.591 \mathrm{bA}$ & $2.460 \mathrm{bA}$ & $2.106 \mathrm{cA}$ & $3.043 \mathrm{aA}$ & 2.558 \\
\hline Sistema 3 & $2.631 \mathrm{abA}$ & $2.790 \mathrm{abA}$ & $2.558 \mathrm{bA}$ & $2.109 \mathrm{cA}$ & $2.904 \mathrm{aA}$ & 2.598 \\
\hline Sistema 4 & $2.473 \mathrm{bcA}$ & $2.720 \mathrm{abA}$ & $2.415 \mathrm{cA}$ & $1.979 \mathrm{dA}$ & $2.991 \mathrm{aA}$ & 2.516 \\
\hline Testemunha & $875 \mathrm{bB}$ & $985 \mathrm{abB}$ & $918 \mathrm{bB}$ & $704 \mathrm{bB}$ & $1.274 \mathrm{aB}$ & 951 \\
\hline Média & 2.203 & 2.392 & 2.200 & 1.795 & 2.643 & 2.246 \\
\hline
\end{tabular}

Médias seguidas pelas mesmas letras, minúsculas na linha (horizontal) e maiúsculas na coluna (vertical), não diferem estatisticamente entre si pelo teste de Tukey a 5\%. DAE = dias após emergência das plantas de soja $\mathrm{RR}^{\circledR}$.

"sistemas 4 e 1". Ainda nas áreas com os cultivares Valiosa e CD 219, verificou-se que o não-controle de plantas daninhas em pósemergência ocasionou diminuição na altura de plantas de soja, porém não diferindo da altura das plantas associadas ao "sistema 3", e nas áreas semeadas com o cultivar CD 219, também não diferindo do "sistema 1". A utilização do "sistema 3" de aplicação de herbicidas, juntamente com a testemunha, causou redução no crescimento das plantas de soja do cultivar TMG 108 (Tabela 7).

Em geral, observou-se que o cultivar de soja $R^{\circledR}{ }^{\circledR}$ TMG 108 apresentou os maiores valores de altura de plantas, independentemente do sistema de aplicação de herbicidas utilizado, o que corrobora o melhor fechamento de dossel constatado no cultivo dessa variedade.

A produtividade de grãos diferiu entre os cultivares de soja $R^{\circledR}$, de acordo com o sistema de aplicação de herbicidas empregado. Todavia, a produtividade de grãos de cada cultivar não diferiu entre os sistemas de aplicação de herbicidas, sendo a produtividade obtida com a utilização de todos os sistemas superior à da testemunha, onde não se realizou o controle de plantas daninhas em pós-emergência (Tabela 7). Oliveira Júnior et al. (2006) verificaram incremento na produtividade da soja quando se realizou o controle das plantas daninhas em pós-emergência. Vangessel et al. (2001b) constataram alta produtividade de soja tolerante a glyphosate quando foi feita uma aplicação desse herbicida em pré-semeadura seguida de outra aplicação em pós-emergência, quando a cultura se encontrava nos estádios fenológicos compreendidos entre V2 e V4. Entre os cultivares de soja $\mathrm{RR}^{\circledR}$, verificou-se que o TMG 108 apresentou maior produtividade de grãos em todos os sistemas de aplicação de herbicidas, inclusive nas parcelas da testemunha, mas não diferindo no "sistema 1" do cultivar P98R91, no "sistema 3" dos cultivares P98R91 e M-SOY 8585, no "sistema 4" do cultivar P98R91 e na testemunha, também do cultivar P98R91. No cultivar de soja RR ${ }^{\circledR}$ CD 219 registrou-se a menor produtividade de grãos quando da implementação de todos os sistemas de aplicação de herbicidas. Apenas nas parcelas da testemunha a produtividade de grãos do cultivar CD 219 não diferenciou daquela dos cultivares M-SOY 8585, Valiosa e P98R91. Marques \& Benez (2000) e Valentini et al. 
(2001), trabalhando com diferentes sistemas de manejo de herbicidas sobre a vegetação espontânea e plantas de cobertura nas culturas de milho e feijão, respectivamente, verificaram que não houve efeito algum dos sistemas avaliados sobre a produtividade de grãos.

Os resultados de controle das plantas daninhas, bem como da produtividade de grãos, demonstram que apenas uma aplicação de herbicidas na dessecação de manejo, associada a uma aplicação em pós-emergência, de preferência mais precocemente, é suficiente para se obter controle eficiente das plantas daninhas, garantindo a manutenção do potencial produtivo das cinco variedades avaliadas. No entanto, deve-se ressaltar que esses resultados podem ser atingidos em áreas onde se realizam outros métodos de controle de plantas daninhas, como o cultural, o que reflete na redução do banco de sementes de plantas daninhas no solo e, conseqüentemente, no potencial de interferência dessas espécies nas lavouras comerciais.

\section{LITERATURA CITADA}

BARROS, A. C. Eficiência da mistura em tanque glyphosate + carfentrazone-ethyl na dessecação de plantas daninhas.

R. Bras. Herbic., v. 2, n. 1, p. 31-35, 2001.

BIOTECH BRASIL. "Cultivo de transgênicos no CentroOeste". Disponível em: <http://www.biotechbrasil.bio.br/ 2007/01/24/cultivo-de-transgenicos-no-centro-oeste-superao-sul-do-pais> Acesso em: 2 fevereiro de 2007.

CARVALHO, F. T.; VELINI, E. D. Períodos de interferência de plantas daninhas na cultura da soja I - Cultivar IAC 11. Planta Daninha, v. 19, n. 3, p. 317-322, 2001.

EMPRESA BRASILEIRA DE PESQUISA AGROPECUÁRIA - EMBRAPA. Centro Nacional de Pesquisa de Solos (Rio de Janeiro, RJ). Sistema Brasileiro de Classificação de Solos. Rio de Janeiro: 1999. 412 p.

FOLONI, L. L. et al. Aplicação de glifosato em pósemergência, em soja transgênica cultivada no cerrado. R. Bras. Herbic., v. 4, n. 3, p. 47-58, 2005.
JAKELAITIS, A. et al. Controle de Digitaria horizontalis pelos herbicidas glyphosate, sulfosate e glyphosate potássico submetidos a diferentes intervalos de chuva após a aplicação. Planta Daninha, v. 19, n. 2, p. 279-285, 2001.

MACIEL, C. D. G.; CONSTANTIN, J. Misturas de flumioxazin com glyphosate e sulfosate para o manejo de plantas daninhas em citros. R. Bras. Herbic., v. 3, n. 2, p. 109-116, 2002.

MARQUES, J. P.; BENEZ, S. H. Manejo da vegetação espontânea para a implantação da cultura do milho (Zea mays L.) em plantio direto e preparo convencional do solo. Energia Agric., v. 15, n. 1, p. 13-26, 2000.

MENDELSON, J. Round up: o herbicida mais vendido no mundo. Ecologist, v. 28, p. 24-27, 1998.

OLIVEIRA JÚNIOR, R. S. et al. Interação entre sistemas de manejo e de controle de plantas daninhas em pós-emergência afetando o desenvolvimento e a produtividade da soja.

Planta Daninha, v. 24, n. 4, p. 721-732, 2006.

PIRES, F. R. et al. Potencial competitivo de cultivares de soja em relação às plantas daninhas. Planta Daninha, v. 23, n. 4 , p. $575-581,2005$.

PITELLI, R. A. Interferência de plantas daninhas em culturas agrícolas. Inf. Agropec., v. 11, n. 129, p. 16-27, 1985.

PROCÓPIO, S. O. et al. Efeitos de dessecantes no controle de plantas daninhas na cultura da soja. Planta Daninha, v. 24, n. 1, p. 193-197, 2006.

SWANTON, C. J. et al. An economic assessment of weed control strategies in no-till glyphosate-resi stant soybean (Glycine max). Weed Technol., v. 14, n. 3, p. 755-763, 2000.

VALENTINI, M. H. E. et al. Épocas de manejo químico de coberturas de solo para a cultura do feijoeiro. Sci. Agríc., v. 2 , n. 1-2, p. 11-16, 2001.

VANGESSEL, M. J.; AYENI, A. O.; MAJEK, B. A. Glyphosate in double-crop no-till glyphosate-resistant soybean: role of preplant applications and residual herbicides. Weed Technol., v. 15, n. 4, p. 703-713, 2001 a.

VANGESSEL, M. J.; AYENI, A. O.; MAJEK, B. A. Glyphosate in full-season no-till glyphosate-resistant soybean: role of preplant applications and residual herbicides. Weed Technol., v. 15, n. 4, p. 714-724, 2001 b. 